\title{
EFFECT OF LASER ETCHING ON BONDING AND DEBONDING OF ORTHODONTIC BRACKETSE
}

\author{
Hany Salah Eldin Eid* and Sahar Ahmed Abd El Halim**
}

\begin{abstract}
Objectives: Comparing effect of surface enamel conditioning when irradiated with Er,Cr:YSGG laser versus typical phosphoric acid etching on shear bond strength of orthodontic brackets and their effect on esthetics of enamel surfaces after debonding.

Methods: Forty freshly extracted premolars were used in this study. Sample was divided into two groups ( $\mathrm{n}=20$ ), group I; enamel etched with $37 \%$ phosphoric acid (3M Unitek, Monrovia, USA) for $15 \mathrm{~s}$. Group II; enamel was irradiated with Er,Cr:YSGG laser ablated with an energy output of $4.5 \mathrm{watt} / 20 \mathrm{hz}(2.78 \mu \mathrm{m}$ wavelength) used for $15 \mathrm{sec}$. Orthodontic brackets (NU-EDGE.022" ROTH RX.TP orthodontics) were bonded to enamel surface of all specimens (Feltik Supreme XT Flowable, 3M/ESPE). The teeth were placed in Lloyd universal testing machine at crosshead speed of $0.5 \mathrm{~mm} /$ minute, and the shear force to remove the brackets was recorded. The bracket bases and enamel surfaces were examined after debonding under a light stereomicroscope at 20 $\mathrm{x}$ magnification and the adhesive remnant index (ARI) scores were assigned to each specimen. Statistical analysis was conducted using SPSS. The SBS data were compared with an unpaired $t$ test. Statistical significance for both tests was defined as $p<0.05$. The distributions of ARI scores were compared with an unpaired t test.
\end{abstract}

Results: A higher shear bond strength mean value was recorded in acid etching group $(14.71 \pm 0.82) \mathrm{Mpa}$, where unpaired $\mathrm{t}$ test revealed that the difference between groups was statistically significant $(\mathrm{P}<0.0001)$. Higher $(\mathrm{ARI})$ mean value was recorded in laser etching group $(2.3 \pm 0.47)$, where unpaired t test revealed that the difference between groups was statistically significant $(\mathrm{P}<0.0001)$.

Conclusions: Er:YAG laser is capable of obtaining optimal bond strength for orthodontic brackets when used as a surface conditioning agent though have lower bond strength, In addition, it leaves the enamel with a rougher surface upon debonding versus typical acid etching techniques.

KEY WORDS: Lasers, Orthodontics, Enamel, Adhesives, Bonding, Demineralization.

* Associate Professor, Orthodontic Dep., Faculty of Dentistry, Misr University for Science \& Technology, $6^{\text {th }}$ of October City, Giza, Egypt.

** Associate Professor, Operative Dep. Faculty of Dentistry, Misr University for Science \& Technology $6^{\text {th }}$ of October City, Giza, Egypt. 


\section{INTRODUCTION}

For almost thirty years, advances in orthodontic bonding techniques, has not ceased the meticulous efforts to further perfect this crucially important procedure. The fruit of such efforts has led to a successful bond interface between brackets and enamel surface. However, studies have shown that clinical bond failure still occurs with $5 \%$ to $7 \%$ of brackets bonded with light cured or chemical-cured composite resins for different reasons (O'Brien et al 1989), (Underwood et al 1989). ${ }^{1,2}$

Orthodontic brackets are required to; withstand an optimal orthodontic force, bare the masticatory loads, and should be easily removed at the end of the treatment with no or minimal damage to the tooth surface (Oesterle et al 2004), (Mehta et al 2008). ${ }^{3,4}$

Possible enamel demineralization followed by white spot formation cannot be ignored in such procedure, as it is not uncommon in orthodontic bonding and debonding agenda when fixed hardware is used, where the use of traditional acid based etching agent can tremendously contribute to the serious of events leading to damage to tooth surface.

Dental enamel, the hardest and most mineralized tissue in the human body, makes up the outer layer of tooth crowns. Although mature enamel contains 95 wt $\%$ carbonated apatite and less than 1-2\% organic material and water, the forming early secretary enamel consists of approximately $30 \mathrm{wt} \%$ mineral, $20 \mathrm{wt} \%$ organic matrix (protein), and $50 \mathrm{wt} \%$ water (Fukae et al 2007), (Smith 1998), ${ }^{5,6}$ The possibility of demineralization of the enamel at the labial surfaces of teeth during and after orthodontic therapy, constitute a major problem in clinical dentistry. It was reported that, enamel demineralization developed in nearly $50 \%$ of orthodontic patients and progressed as rapidly as only 4 weeks which is the usual time between orthodontic visits forming the enamel white spot lesions. The occurrence is believed to be due to many factors among them, increased numbers of streptococcus mutans and other pathological microbes in the biofilm, as well as compromised oral hygiene (Smith 1998). ${ }^{6}$

Obtaining good occlusion after the conclusion of any orthodontic case is desired by both the operator and the patient. However, if a damaged enamel surface layer in structure or appearance is produced after removal of bonded orthodontic appliance, it would be of great devastation no matter how perfect the occlusion has become.

Laser therapy in dentistry is known to deliver hard and soft tissue treatment that could attempt to make the patient experience somewhat easier than conventional methods. The use of lasers in the medical field is very old, in dentistry, only during the last two decades have commercially available lasers been used as adjunctive in delivering tissue management conducive to achieving hard or soft tissue procedures (Abo El Naga 2012). ${ }^{7}$

The strength of the bond between the orthodontic bracket and the enamel surface is multifactorial, mainly; the bracket base meshwork design mechanism, the adhesive or bonding resin, and the tooth enamel surface treatment (Urabe 1999). ${ }^{8}$ A multitude of different surface treatment methods are available for orthodontic use, in 1955, the introduction of orthophosphoric acid etching and has been widely used to prepare tooth enamel for bonding orthodontic brackets (Urabe 1999). ${ }^{8}$ Erbium:yttrium-aluminumgarnet (Er:YAG) and neodymium:yttrium-aluminum-garnet (Nd:YAG) lasers have been proposed as alternatives tooth phosphoric acid etching (Üşümez et al 2002), (Ozer et al 2008)..$^{9,10}$

Over the years, adhesive remnant index (ARI) scores have been one of the most frequently evaluated aspects in studies on orthodontic adhesives. $\mathrm{A}^{\circ}$ rtun and Bergland1 used an Adhesive Remnant Index (ARI) system to evaluate the amount of adhesive left on the tooth after debracketing $\left(\mathrm{A}^{\circ}\right.$ rtun and Bergland 1984). ${ }^{11}$ 
Therefore, in this study, laser therapy was tested to investigate the potential of offering an opportunity to provide optimum sheer bond strength in combination with providing a more healthy spotless enamel surface after bracket debonding than conventional acid etching products, employing the ARI method for evaluation.

\section{MATERIALS AND METHODS}

Forty human freshly extracted caries-free upper premolars were used in this study. The teeth were obtained from orthodontic patients of outpatient clinic, Department of Orthodontics, Faculty of Dentistry, Misr University, aged between thirteen and twenty years, with no gender preference. All patients treated at any dental Department at MISR University were consented verbally (the consent procedure was approved by the ethics committee). Extracted teeth were washed under running water and were stored at $4^{\circ} \mathrm{C}$ in a solution of $0.1 \%$ $(\mathrm{wt} / \mathrm{vol})$ thymol and were used within 1 week after extraction. The apices were embedded in plaster to facilitate identification and manipulation.

Sample was divided into two groups $(n=20)$ according to the surface enamel etching technique, group I; [control group] enamel etched with $37 \%$ phosphoric acid (3M Unitek, Monrovia, USA) for $15 \mathrm{~s}$, thoroughly rinsed with distilled water for $60 \mathrm{~s}$ and gently air dried. Group II; enamel was irradiated with Er,Cr:YSGG laser ablated with an energy output of 4.5 watt $/ 20 \mathrm{hz}(2.78 \mu \mathrm{m}$ wavelength $)$ used for $15 \mathrm{sec}$ at 45 degree angulations working distance $5 \mathrm{~mm}$ on a square size $4 \times 4 \mathrm{~mm}$ on buccal surface. Orthodontic brackets (NU-EDGE.022" ROTH RX.TP orthodontics) were bonded to enamel surface of all specimens in both groups (Feltik Supreme XT Flowable, 3M/ESPE). They were placed on the bonding surfaces by one operator. Excess adhesive was removed with a sharp explorer, and the samples were light-cured using the Ortholux ${ }^{\mathrm{TM}}$ LED Curing Light (App. 1000 mW/cm2) (3M Unitek Dental
Products) for $10 \mathrm{~s}$ through the bracket according to the manufacturer's recommendations. After 24 hrs., the teeth were placed in Lloyd universal testing machine at crosshead speed of $0.5 \mathrm{~mm} /$ minute, and the shear force to remove the brackets was recorded, each sample was mounted on the lower fixed compartment of a computer-controlled materials testing machine (Model LRX-plus; Lloyd Instruments Ltd., Fareham, UK) with a load cell of $5 \mathrm{kN}$, and data were recorded using computer software (Nexygen-MT; Lloyd Instruments). Then, the samples were subjected to compressive loading in the occlusogingival direction at a crosshead speed of $0.5 \mathrm{~mm} / \mathrm{min}$ via a mono-beveled chisel-edged rod attached to the upper movable compartment of the testing machine. The chisel tip was positioned to only touch the base of the bracket. The maximum failure load was recorded in N. Failure was manifested by the displacement of bracket and confirmed by sudden drop along the load-deflection curve recorded by computer software (Nexygen-MT; Lloyd Instruments Ltd). To express the bond strength in MPa, the maximum failure load was divided by the bracket base area provided by the manufacturer. The bracket bases and enamel surfaces were examined under a light stereomicroscope at 20x magnification, and the adhesive remnant index (ARI) scores were assigned to each specimen (Artun and Bergland, 1984). The scores were assessed as follows: 0 indicated that no adhesive was left on the tooth in the bonding area; 1 indicated that less than half of the adhesive was left on the tooth; 2 indicated that more than half was left on the tooth; and 3 indicated that all adhesive was still on the tooth, with a distinct impression of the bracket mesh on the remaining adhesive surface.

Statistical analysis was conducted using SPSS. The SBS data were compared with an unpaired $\mathrm{t}$ test. Statistical significance for both tests was defined as $\mathrm{p}<0.05$. The distributions of ARI scores were compared with an unpaired $t$ test. 


\section{RESULTS}

\section{1-Shear bond strength (Mpa)}

A higher mean value was recorded in acid etching group (14.71 \pm 0.82$) \mathrm{Mpa}$. Unpaired t test revealed that the difference between groups was statistically significant $(\mathrm{P}<0.0001)$, (Table1, Fig.1)

\section{2-Adhesive remnant index (ARI)}

A higher mean value was recorded in laser etching group $(2.3 \pm 0.47)$. Unpaired t test revealed that the difference between groups was statistically significant $(\mathrm{P}<0.0001)$ (Table 2, Fig.2).

TABLE (1) Descriptive statistics of Shear bond strength (Mpa) and significance of difference between groups (Unpaired t test).

\begin{tabular}{|c|c|c|c|c|c|c|c|c|c|c|}
\hline Groups & $\mathrm{N}$ & Mean & $\begin{array}{c}\text { Std. } \\
\text { Deviation }\end{array}$ & $\begin{array}{c}\text { Std. Error } \\
\text { Mean }\end{array}$ & $\begin{array}{c}\text { Mean } \\
\text { Difference }\end{array}$ & $\begin{array}{c}\text { Std. Error } \\
\text { Difference }\end{array}$ & $\begin{array}{c}95 \% \text { CI } \\
\text { lower }\end{array}$ & $\begin{array}{c}95 \% \text { CI } \\
\text { upper }\end{array}$ & $\mathrm{t}$ & $\mathrm{p}$ \\
\hline Acid etching group & 20 & 14.7118 & .81671 & .18262 & 5.6 & .58 & 4.4 & 6.8 & 9.648 & $<0.0001 *$ \\
\hline Laser etching group & 20 & 9.1110 & 2.46425 & .55102 & & & & & & \\
\hline
\end{tabular}

*significant

95\% CI $=95 \%$ Confidence Interval of the Difference

TABLE (2) Descriptive statistics of Adhesive remnant index (ARI) and significance of difference between groups (Unpaired t test).

\begin{tabular}{|c|c|c|c|c|c|c|c|c|c|c|}
\hline Groups & $\mathrm{N}$ & Mean & $\begin{array}{c}\text { Std. } \\
\text { Deviation }\end{array}$ & $\begin{array}{c}\text { Std. Error } \\
\text { Mean }\end{array}$ & $\begin{array}{c}\text { Mean } \\
\text { Difference }\end{array}$ & $\begin{array}{c}\text { Std. Error } \\
\text { Difference }\end{array}$ & $\begin{array}{c}95 \% \text { CI } \\
\text { lower }\end{array}$ & $\begin{array}{c}95 \% \text { CI } \\
\text { upper }\end{array}$ & $\mathrm{t}$ \\
\hline Acid etching group & 20 & .9500 & .39403 & .08811 & 1.35 & .1372 & 1.072 & 1.628 & 9.842 & $<0.0001 *$ \\
\hline Laser etching group & 20 & 2.3000 & .47016 & .10513 & & & & & & \\
\hline
\end{tabular}

*significant

95\% CI=95\% Confidence Interval of the Difference

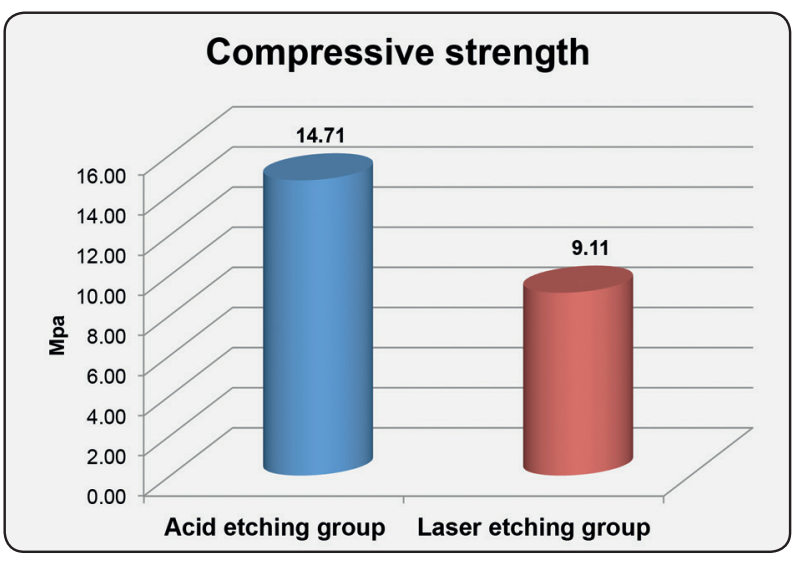

Fig. (1) Column chart showing mean compressive strength in acid etch and laser etch group.

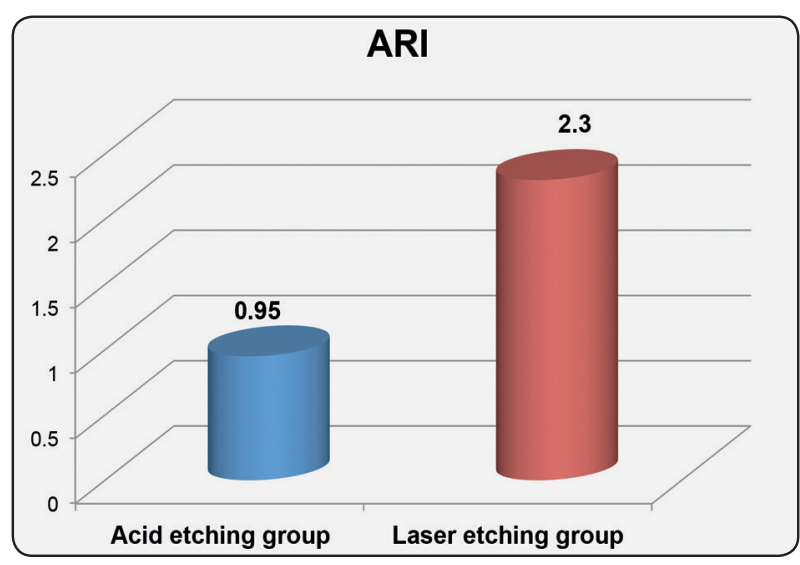

Fig. (2) Column chart showing mean ARI in acid etch and laser etch group. 


\section{DISCUSION}

When addressing laser etching of enamel, many authors suggested that the laser etching is capable of creating remineralization micro spaces that traps free ions and produces a surface that is more acid resistant and less susceptible to caries, as a result, it did not need water spraying or air drying saving precious chair time (sawan et al 2015), (Aglarci et al 2016). ${ }^{12,13}$ On the other hand, where phosphoric acid etching has proven to be a reliable method of bonding resins to enamel, a potential disadvantage of enamel acid etching is demineralization of the most superficial layer, a matter of concern for every orthodontic practitioner. As a result of demineralization, the enamel surface is more susceptible to acid attack and caries (Nalçaci et al 2017). ${ }^{14}$

Orthodontic brackets in action are prone to variety of forces. Bond strength is affected by various factors like the surface area, conditioning procedures, type of adhesive used, bracket base design, bracket base preparation, and bonding procedure (Velo_et al 2002), (Kaul and Dhanani 2017). ${ }^{15,16}$ The various researches that have been conducted to eliminate or minimize the factors leading to unintentional debonding of orthodontic brackets during treatment were pivotal, as successful orthodontic treatment relies to a large extent on the sustained character of forces without interruption, otherwise, treatment time could be extended leading to compromised health of the periodontium and masticatory apparatus as well as patient and operator aggravation (Eid 2012). ${ }^{17}$ In order to minimize orthodontic treatment disruption, the forces placed on the brackets should be limited as much as possible to only predetermined torqueing forces required to move the tooth or group of teeth to the desired position. These forces should be only produced by the force generating mechanism in the appliance. That could be achieved by eliminating or at least minimizing other factors or stresses that could be added to the therapeutic useful forces falling on the brackets. Knowing that, occlusal loading is the major force to be withstood intraorally to prevent failure of the orthodontic brackets (Reynolds 1975)..$^{18}$

When deciding what bond strength is considered optimal value, two factors must be kept in mind, bond strength able to withstand sheer forces applied while brackets are in action, in addition to the ease and safety of debonding in favor of enamel surface (Ogaard et al 2004), (Tavarez et al 2017). ${ }^{19}$, ${ }^{20}$ Aside from the mechanical efficiency of bonding procedure, comes another factor not to be taken lightly, which is how friendly the gadgets used to prepare the enamel surface to receive and hold the bonding composite, in other words, the etching procedure. It was not uncommon to find white spot lesions from acid attack of conventional acid etching commonly used for enamel conditioning. Therefore, interest in alternative enamel conditioning methods has risen greatly in the past few years. The use of lasers for etching enamel surface has been debated in many researches. Although some researchers (loos et al 1994), (Guiraldo et al 2016) ${ }^{21,22}$ agree that laser etching is not suitable for etching enamel, others (Fuhrmann et al 2001), (Goel et al $2017)^{23,24}$ reported that laser irradiation can be used to etch tooth enamel.

Early use of laser bonding was found to be time consuming and bond strength less efficient than conventional acid etching as reported by Dai P Roberts-Harry (Khajuria et al 2016). ${ }^{25}$ With the introduction of hard tissue lasers like Erbium-doped: yttrium-aluminum-garnet systems, it is possible to ablate dental hard tissues like enamel and dentin without thermal side effects (Usumez et al 2002). ${ }^{9}$ The efficiency of Er:YAG laser to effectively ablate dental hard tissues is related to its $2940 \mathrm{~nm}$ wavelength emission, which is coincident with the main absorption band of water and hydroxyapatite of enamel. Consequently, devastating thermal 
side effects on enamel and dentin were greatly minimized (Basaran et al 2007), (Ewoldsen and Demke 2001) ${ }^{26,27}$ In addition, Er:YAG laser etching was found to be painless and does not involve either vibration or heat, and the easy maneuvering of the laser apparatus is encouraging to use routinely in similar dental tasks (Usumez et al 2002), (Aglarci et al 2016)..$^{9,13}$

In the present study, a higher sheer bond strength mean value was recorded in acid etching group (14.71) versus (9.11) for laser group (table 1, Fig.1). These values though seems less for laser group, still however efficient for orthodontic brackets optimal bond strength values lying between 6-8MPa. Moreover, opposite to what it seems, the bond strength values reported are more favorable in terms of the rather harsh debonding consequences on enamel surface. Meanwhile, other investigations showed that laser and acid etching procedures produced clinically acceptable bond strengths (Ozer et al 2008) ${ }^{10}$.

Evaluation of the bonding composite remnant is crucial to the final process of enamel cleaning after debonding, since satisfactory removal and restoration of the enamel surface to as close to pretreatment condition as possible, depends largely on the amount of remnant left on tooth surface after debonding. In a survey by Campbell et al, some enamel scarring following the removal of bonded brackets is unavoidable regardless of how good and competent the clinician or the instruments used (Campbell 1995). ${ }^{28}$ Therefore, post bonding scaring of enamel is a disadvantage of orthodontic bonding, however, there is no debate that the advantages of bonding outweigh the disadvantages. The clinician therefore, must attempt to return the enamel surface to as near its original condition as possible.

Irradiation of dental hard tissue with lasers of sufficient power leads to a variety of structural and ultra-structural changes of the tissue near the surface. These changes depend on such irradiation parameters as wave length, pulse duration, pulse energy, number of pulses, repetition rate, and beam spot size (Cxokakog et al 2016), (Sobha et al 2016). ${ }^{29,30}$

The parameters of laser exposure in this study have been carefully selected to avoid the ablation threshold of enamel. Although the mechanism is not well understood yet, it is assumed that low boiling point components of hard tissues such as water, collagen or proteins, get quickly vaporized by heating. The rapidly expanding vapor then removes the mineral component, hydroxyapatite. The work on ablation threshold of teeth reported a safety range of $10-15 \mathrm{mj} / \mathrm{mm} 2$, a value beyond which a risk of explosive evaporation level of water causing mass ejection from teeth enamel surface (Karra and Begum 2014), (Masanori et al 2009). ${ }^{31} 32$

In studies of orthodontic adhesive systems, the significance of ARI score system was found to be undeniable. It is a quick and simple method that requires no special equipment. Therefore, during the last decade, ARI scores have been used frequently to evaluate studies of orthodontic adhesives and its impact on enamel surface (Goel et al 2017). ${ }^{24}$

Accurate evaluation of the adhesive remnant, which is crucial in the final process of enamel cleaning after debonding is needed for satisfactory removal and restoration of the enamel surface to as close to pretreatment condition as possible.

In the present study, a higher ARI mean value was recorded in laser etching group (2.3) compared to the acid etching group (0.95) (table 2) (Fig.2). These values meant that debonding of brackets in laser group leads to a rough enamel surface that requires additional care than usual acid etching procedures to clean and restore back to the original enamel condition. 


\section{CONCLUSION}

Within the limitations of this study, it is now clear that Er:YAG laser is capable of obtaining optimal bond strength for orthodontic brackets when used as a conditioning agent . However, it leaves the enamel with a rougher surface upon debonding versus typical acid etching techniques.

Laser advantage over acid etching conditioning lays in attempting to inhibit or minimize caries and white spot lesions due to acid attack of conventional conditioning agents. Further investigations are needed to establish a solid proof of laser beneficiary effect over acid etching agents from that particular point of view.

\section{ACKNOLEGMENT}

The authors would like to thank all the workers and technicians at the laser unit, XXXX University. This research did not receive any specific grant from funding agencies in the public, commercial, or not-for-profit sectors. The authors have declared no conflict of interest.

\section{REFERENCES}

1. O’Brien KD, Read MJ, Sandison RJ, Roberts CT. A visible light activated direct-bonding material: an in vivo comparative study. Am J Orthod Dentofacial Orthop 1989; 95:348-51.

2. Underwood ML, Rawls HR, Zimmerman BF. Clinical evaluation of a fluoride exchanging resin as an orthodontic adhesive. Am J Orthod Dentofacial Orthop 1989;96:93-9.

3. L. J. Oesterle, W. Craig Shellhart, and A. Fisher, "Effect of primer precuring on the shear bond strength of orthodontic brackets," American Journal of Orthodontics and Dentofacial Orthopedics 2004 ;126 (6): 699-702.

4. O. Mehta, S. Saini, and A. Dahiya, "Comparative evaluation of shear bond strength of different bracket base designs in dry and wet environments," Journal of Indian Society of Pedodontics and Preventive Dentistry 2008;26 (7) :104-108.

5. Fukae M, Yamamoto R, Karakida T, Shimoda S, Tanabe T. Micelle structure of amelogenin in porcine secretory enamel. J Dent Res. 2007; 86: 758-63.
6. Smith CE: Cellular and chemical events during enamel maturation. Crit Rev Oral Biol\& Med, 1998; 9:128-161.

7. Abo El Naga A, Eid H, El Shenawi H, Enamel surface evaluation after composite remnants removal using co2 laser. Eg Dental J 2012; 58 no.2: 42-49.

8. Urabe H, Rossouw PE, Titley KC, Yamin C. Combinations of etchants, composite resins, and bracket systems: an important choice in orthodontic bonding procedures. Angle Orthod 1999; 69: 267-275.

9. Üşümez S, Orhan M, Üşümez A. Laser etching of enamel for direct bonding with an Er,Cr:YSGG hydrokinetic laser system. Am J OrthodDentofacialOrthop 2002; 122: 649-656.

10. Ozer T, Basaran G, Berk N. Laser etching of enamel for orthodontic bonding. Am J Orthod Dentofacial Orthop 2008; 134: 193-197.

11. Årtun J, Bergland S. Clinical trials with crystal growth conditioning as an alternative to acid-etch enamel pretreatment. Am J Orthod. 1984;85:333-340.

12. Sawan MN, Hussain N, Alkurdi MM. Etching of Enamel by Laser Energy for Direct Bonding of Orthodontic Appliance and Evaluation of Shear Bond Strength. Energy Procedia 2015; 74:1452-1458.

13. Aglarci C, Demir N, Aksakalli S, Dilber E, Sozer OA, Kilic HS. Bond strengths of brackets bonded to enamel surfaces conditioned with femtosecond and Er:YAG laser systems. Lasers Med Sci. 2016 Aug;31(6):1177-83

14. Sawan M.Na , Hussain Nb , Alkurdi M.Ma. Etching of Enamel by Laser Energy for Direct Bonding of Orthodontic Appliance and Evaluation of Shear Bond Strength. Energy Procedia 2015; (74): 1452 - 1458.

15. Nalçaci R, Temel B, çokakoğlu S, Türkkahraman H, Üsümez S. Effects of laser etching on shear bond strengths of brackets bonded to fluorosed enamel.2017;20(5): 545-551.

16. Velo S, Carano A, and Carano A: Self-etching vs. traditional bonding systems in orthodontics: an in vitro study, Orthodontics \& Craniofacial Research, 2002; vol. 5, no. 3, pp. 166-169.

17. Kaul Y and Dhanani D. LASERS IN ORTHODONTICSA REVIEW .International Journal of Recent Scientific Research 2017; 8( 5) : 16972-16976.

18. Abo El Naga A, Eid H, Shear bond strength comparison of two adhesives following sonic bruhhing. Eg Dental J 2012; 58 no.1: 46-53. 
19. Reynolds Ir. A review of direct orthodontic bonding. Br J Orthod 1975;2:171-8.

20. Ogaard B, Bishara SE, Duschner H. Chapter 3, Enamel effects during bonding-debonding, DMJ 2008;27(3):392399 and treatment with fixed appliances. In: Graber TM, Eliades T, Athanasiou AE (Eds). Risk Management in Orthodontics: Experts' Guid Malpractice, Quintessence Publishing Co, IL, 2004;19-46.

21. Tavarez RRDJ, Bezerra GL, Penha KJDS, Torres CRG, Firoozmand LM. Er:YAG pre-treatment for bonding of orthodontic bracket: 1 year of in vitro treatment Clinical, Cosmetic and Investigational Dentistry 2017; 9 : 19-25.

22. Loos S, Kudlick E, Eichmiller R, Grimm S. Orthodontic bracket bonding strengths: Laser etched vs acid etched. Am J OrthodDentofacOrthop 1994;112(4):471.

23. Guiraldo RD, Berger SB, Rocha FDS, BPereira GMR, Aleixo AR, Correr AB,Contreras EFR, GoniniJúnior R and Lopes MB. Evaluation of shear strength of brackets with different dental composites and enamel roughness. Appl Adhes Sci 2016; 4:8

24. Fuhrmann R, Gutknecht N, Magunski A, Lampert F, Diedrich P. Conditioning of enamel with Nd:YAG and $\mathrm{CO} 2$ dental laser systems and with phosphoric acid. An in vitro comparison of the tensile bond strength and the morphology of the enamel surface. J OrofacOrthop 2001; 62(5):375-86.

25. Goel A, Singh A, Gupta T, Gambhir RS. Evaluation of surface roughness of enamel after various bonding and clean-up procedures on enamel bonded with three differ- ent bonding agents: An in-vitro study. J Clin Exp Dent. 2017;9(5):e608-616

26. Khajuria AK, Prasantha GS , Mathew S, Madhavi, Khan $\mathrm{Y}$ and Adeeba. LASERS in Orthodontics. Journal of Dental \& Oro-facial Research 2016; 12 (2 ):20-24.

27. Usumez S, Orhan M, Usumez A. Laser etching of enamel for direct bonding with an $\mathrm{Er}, \mathrm{Cr}$ : YSGG hydrokinetic laser system. Am J OrthodDentofac Orthop 2002;122:649-56.

28. Basaran G, Özer T, Berk N, Hamamc O. Etching Enamel for Orthodontics with an Erbium, Chromium:YttriumScandium- Gallium-Garnet laser system. Angle Orthod 2007; 77(1):117-24.

29. N Ewoldsen, R S Demke. A review of orthodontic cements and adhesives. American Journal of Orthodontics and Dentofacial Orthopedics; 120(2001):45.

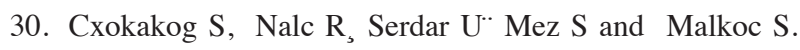
Effects of Different Combinations of Er:YAG Laser-Adhesives on Enamel Demineralization and Bracket Bond Strength. Photomedicine and Laser Surgery 2016; 34( 4):164-170.

31. Sobha VV, Varma NS, AjIth VV. Comparative evaluation of laser etching and acid etching: An in vitro study International Journal of Laser Dentistry. 2016;6(1):6-11.

32. Karra A, Begum M. Lasers in orthodontics. International Journal of Contemporary Dental and Medical Reviews 2014; 5:1- 5 .

33. Masanori OMAE et al, XPS analysis of the dentin irradiated by Er:YAG laser. Dental Materials Journal 2009; 28(4): 471-476. 